\title{
CALCIUM AND ZINC IN THE ENDOMETRIUM AND UTERINE FLUSHINGS OF THE ROE DEER (CAPREOLUS CAPREOLUS) DURING DELAYED IMPLANTATION
}

\author{
R. J. AITKEN* \\ Department of Veterinary Clinical Studies, \\ School of Veterinary Medicine, Cambridge CB3 OES
}

(Received 1st October 1973)

\begin{abstract}
Summary. The concentration of zinc in the endometrium of the roe deer was maintained at a constantly high level throughout delayed implantation and at the time of rapid embryonic growth. By contrast, the zinc content of the uterine flushings was uniformly low and often undetectable $(<0 \cdot 1 \mu \mathrm{g} / \mathrm{ml})$.

The concentration of calcium in the endometrium showed a highly significant $(P<0 \cdot 001)$ increase during delayed implantation reaching maximal levels upon the resumption of rapid embryonic growth. The calcium content of the uterine flushings showed a small but significant $(P<0.001)$ rise in the late stages of diapause followed by a further marked increase during the rapid elongation of the blastocyst in January.
\end{abstract}

\section{INTRODUGTION}

The phenomenon of delayed implantation in the roe deer (Capreolus capreolus) illustrates the stringent control that the uterus is capable of exerting over embryonic growth. In this species, the blastocyst loses its zona pellucida shortly after ovulation in August and then enters a 5-month phase of dormancy referred to as delayed implantation or embryonic diapause (Short \& Hay, 1966). The blastocyst does exhibit limited growth during this phase, its diameter increasing from about 1 to $5 \mathrm{~mm}$, but it is not until the beginning of January that a normal rate of embryonic growth is resumed and the blastocyst suddenly elongates. The rôle of the uterus in controlling the growth of the blastocyst has been implicated in an ultrastructural study of the roe deer endometrium (Aitken, Burton, Hawkins, Kerr-Wilson, Short \& Steven, 1973). Delayed implantation was characterized by the gradual accumulation of clear vesicles in the apical region of the endometrial gland cells, while the onset of blastocyst elongation was associated with the sudden release of these vesicles into the lumina of the glands. The release of an endometrial secretion at the time of rapid embryonic growth was also suggested in a study of the surface ultrastructure of the endometrium by scanning electron microscopy and by the

* Present address: Department of Genetics, West Mains Road, Edinburgh. 
quantitative biochemical analysis of uterine flushings (Aitken, 1974). It seems likely that the uterus is able to restrain the growth of the roe deer blastocyst during delayed implantation by witholding the release of an endometrial secretion capable of inducing and supporting the elongation of the embryo.

An investigation into the concentration of endometrial zinc during delayed implantation was prompted by the results of Lutwak-Mann \& McIntosh (1969) and McIntosh \& Lutwak-Mann (1972), who discovered that the first week of pregnancy in the rabbit was associated with an increased concentration and a decreased turnover of zinc in the endometrium. Hagenfeldt, Plantin \& Diczfalusy $(1970,1973)$ also observed a marked increase in the zinc concentration of the human endometrium during the late secretory phase of the menstrual cycle. Thus, in both the rabbit and women, a significant increase in zinc concentration was observed at a time when the free blastocysts would be dependent on the secretions of the progestational endometrium for their maintenance.

The importance of calcium to the early stages of pregnancy was suggested in the study of Lutwak-Mann \& McIntosh (1971). These authors established that the rabbit endometrium was a calcium-rich tissue and although the concentration of calcium showed no significant changes during progestation, the turnover of ${ }^{45} \mathrm{Ca}$ was considerably slower in the pregnant than in the nonpregnant, oestrous endometrium.

Experiments involving the parenteral administration of labelled ${ }^{45} \mathrm{Ca}$ and ${ }^{65} \mathrm{Zn}$ have demonstrated that the transport of maternal calcium and zinc from the endometrium to the free-lying blastocysts is achieved by means of the uterine fluids (Lutwak-Mann \& McIntosh, 1971; McIntosh \& Lutwak-Mann, 1972). The presence of calcium in the viscous progestational secretions of the rabbit uterus was also suggested by the observation that the calcium content of 5- and 6-day blastocysts could be considerably lowered by rinsing the surface free of adherent material presumably derived from the endometrium. Calcium has also been detected in the uterine fluids of the cow (Schultz, Fahning \& Graham, 1971) and in uterine flushings obtained from the rat, rabbit and sheep (Heap, 1962).

The purpose of this paper is to describe the concentration of calcium and zinc in the endometrium and uterine flushings of the roe deer during delayed implantation with particular reference to the release of the endometrial secretion in January.

\section{Animals}

\section{MATERIALS AND METHODS}

The study was based on an examination of roe deer shot during the annual Forestry Commission cull at Thetford Chase, Norfolk. Immediately after death, the uterus was removed, put on ice in a thermos flask and transported, together with the rest of the carcase, to a field laboratory where the uterine horns were separated and flushed from the tubal end with $20 \mathrm{ml}$ of $0.85 \%$ phosphatebuffered saline. As soon as the blastocysts or elongating embryos had been removed from the flushings, the latter were frozen, along with the uterine horns, at $-20^{\circ} \mathrm{C}$ until the time of analysis. 
The animals were aged by counting the number of white growth rings visible in the dental cement after sectioning the first molar tooth according to the method of Mitchell $(1963,1967)$. The animals were judged to have had a previous pregnancy if the uterine arteries were well developed (Short \& Hay, 1966).

\section{Determination of calcium and zinc}

The concentration of calcium and zinc in the endometrium of twenty-seven animals was determined by atomic absorption spectrophotometry. Endometrial digests were prepared by weighing samples of tissue into $30-\mathrm{ml} \mathrm{Kjeldahl}$ flasks and digesting the material overnight with $1 \mathrm{ml}$ fuming $\mathrm{HNO}_{3}$. One drop of $\mathrm{H}_{2} \mathrm{O}_{2}$ was subsequently added and the mixture was evaporated until 0.05 to $0.1 \mathrm{ml}$ fluid remained. The residue was taken up with either $4 \mathrm{ml}$ of $0.01 \mathrm{~m}-\mathrm{HCl}$ in the case of zinc or $4 \mathrm{ml}$ of $0.01 \mathrm{~m}-\mathrm{HCl}$ containing $1 \% \mathrm{LaCl}_{3}$ (to overcome the suppressive effect of phosphate ion on calcium absorption) when determining calcium.

The concentration of calcium and zinc in the uterine flushings of roe deer was estimated on samples obtained from thirty-seven animals. No special treatment of the flushings was required for the determination of zinc but for the determination of calcium, ethylenediaminetetra-acetic acid $(0.8 \mathrm{ml}$ of $3.75 \%$ EDTA- $\mathrm{Na}_{2} / 3.2 \mathrm{ml}$ flushings) was added to overcome the interference of calcium absorption by phosphate ion.

Standard curves were constructed using between 0.5 and $8 \mu \mathrm{g}$ of calcium or zinc, EDTA-Na $\mathrm{Na}_{2}$ or $\mathrm{LaCl}_{3}$ being incorporated into the calcium standards where appropriate.

All determinations were carried out in duplicate.

Zinc in the endometrium

\section{RESULTS}

The concentration of zinc in the endometrium did not show any significant changes during the period of delayed implantation or on the resumption of rapid embryonic growth (Text-fig. 1). The mean zinc concentration recorded in roe deer carrying diapausing blastocysts was $16 \cdot 63 \pm 2 \cdot 25 \mu \mathrm{g} / \mathrm{g}$ wet wt (mean \pm S.D.) compared with a value of $14.54 \pm 3.04 \mu \mathrm{g} / \mathrm{g}$ wet wt for animals carrying elongating embryos. Since these means were not significantly different $(P>0.05)$, the results were combined to give an overall figure of $15 \cdot 80 \pm 2 \cdot 76 \mu \mathrm{g} / \mathrm{g}$ wet wt. There appeared to be a great deal of variation in zinc concentration between animals which was not related to age or parity.

\section{Zinc in the uterine flushings}

Very low levels of zinc were detected in the uterine flushings at all stages of delayed implantation and embryonic growth. In thirty-six samples, the concentration was between 0.1 and $0.3 \mu \mathrm{g} / \mathrm{ml}$ in sixteen, and less than $0.1 \mu \mathrm{g} / \mathrm{ml}$ in the remainder.

\section{Calcium in the endometrium}

The concentration of calcium in the endometrium showed significant 


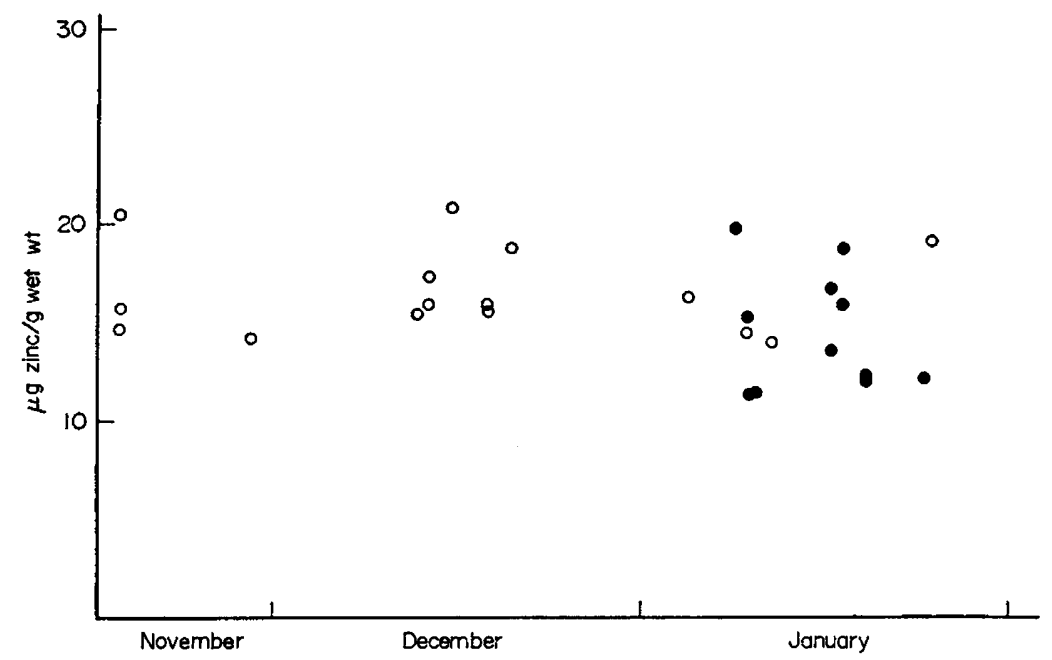

TEXT-FIG. 1. Concentration of zinc in the endometrium of roe deer during delayed implantation. Results plotted as the mean of duplicate determinations. $O$, Blastocyst in the uterus; $\bullet$, embryo in the uterus.

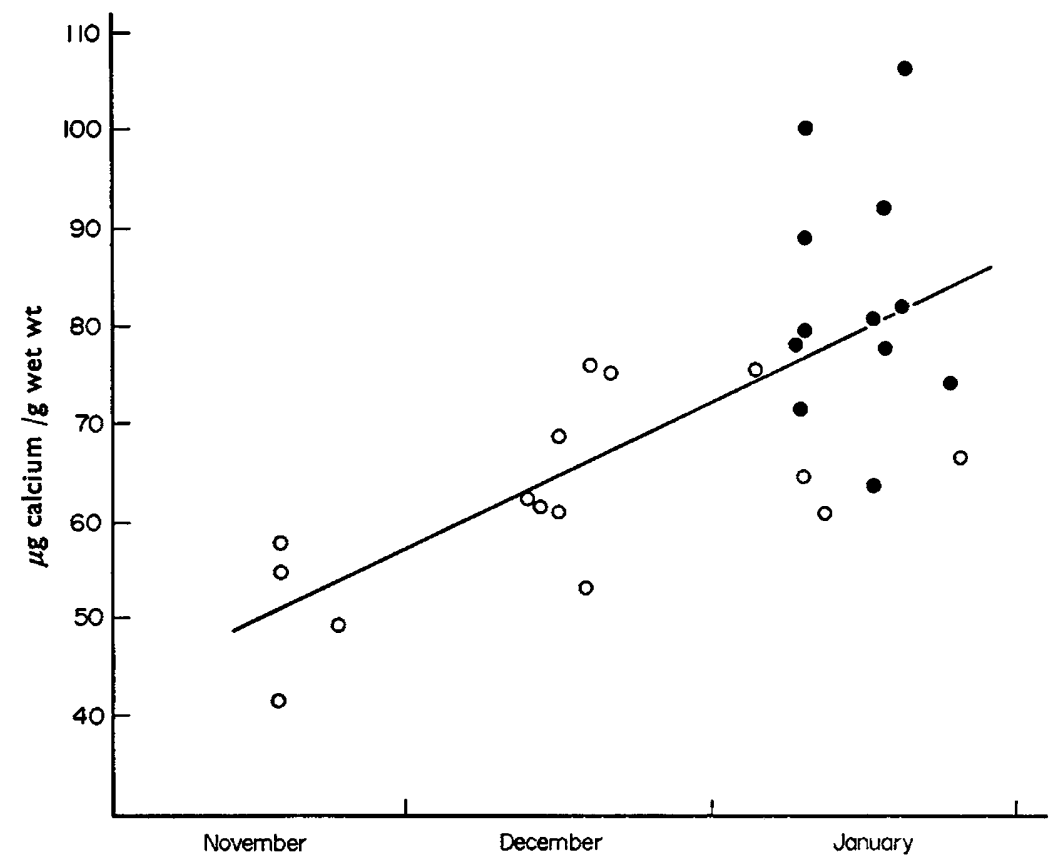

TEXT-FIG. 2. Concentration of calcium in the endometrium of roe deer during delayed implantation. Results plotted as the mean of duplicate determinations; linear regression line given by formula: $y=50.73+0.48 x$, where $y=$ concentration of calcium and $\mathbf{x}=$ date $(17$ th November $=$ Day 1$) .0$, Blastocyst in the uterus; $\bullet$, embryo in the uterus. 
changes during delayed implantation and at the time of embryonic elongation. The mean value of $62.00 \pm 9.96 \mu \mathrm{g} / \mathrm{g}$ wet wt recorded for animals during delayed implantation was significantly lower $(P<0.001)$ than the figure obtained during the phase of rapid elongation, which was $83.01 \pm 12.04 \mu \mathrm{g} / \mathrm{g}$ wet wt. This difference was significant whether parametric ( $t$ test) or non-parametric (MannWhitney U) statistics were used on the data.

A highly significant correlation was observed $(P<0.001)$ between the concentration of endometrial calcium and the date on which the embryos were recovered $(r=0 \cdot 682)$. It was therefore possible to fit a linear regression line to the data describing the relationship between the duration of delayed implantation and calcium concentration (Text-fig. 2). This relationship was given by the formula: $y=50 \cdot 73+0 \cdot 48 x$, the standard deviation about the regression line being $\pm 11.26 \mu \mathrm{g} / \mathrm{g}$ wet wt. The results indicated that embryonic elongation normally occurred when the calcium concentration had risen above about $75 \mu \mathrm{g} / \mathrm{g}$ wet wt.

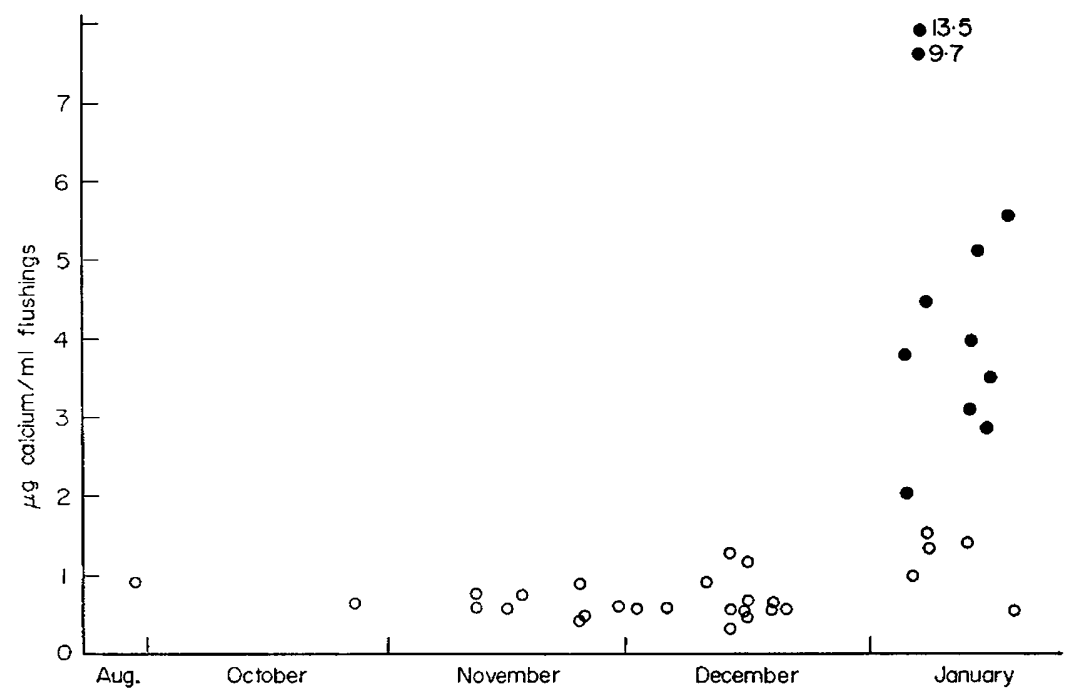

TEXT-FIG. 3. Concentration of calcium in uterine flushings from roe deer during delayed implantation. Results plotted as the mean of duplicate determinations. 0 , Blastocyst in the uterus; $\bullet$, embryo in the uterus.

\section{Calcium in the uterine flushings}

The results of this analysis revealed a highly significant rise in the calcium content of the uterine flushings at the time of rapid embryonic elongation in January (Text-fig. 3). During delayed implantation, the mean concentration of calcium in the uterine flushings was $0.75 \pm 0.32 \mu \mathrm{g} / \mathrm{ml}$ while the levels rose during the phase of embryonic growth to a value of $5.26 \pm 3.38 \mu \mathrm{g} / \mathrm{ml}$; the difference between these means was highly significant $(P<0.001)$. The highest levels of calcium were recorded during the early phase of embryonic growth when the crown-rump length of the embryos was less than $0.75 \mathrm{~cm}$.

A significant difference was also found in the calcium content of the uterine 
flushings at different stages of delayed implantation. While the mean concentration of calcium in the uterine flushings collected between 6 August and 31 December was $0.67 \pm 0.23 \mu \mathrm{g} / \mathrm{ml}$, the mean in January for animals still carrying blastocysts in diapause (i.e. in the late stages of delayed implantation) was $1 \cdot 18 \pm 0 \cdot 42 \mu \mathrm{g} / \mathrm{ml}$. The difference between these means was highly significant when the data were analysed with a $t$ test $(P<0.001)$ but less significant when a non-parametric statistic, the Mann-Whitney $U$, was applied $(P=0.012)$.

Contamination of the uterine flushings by embryonic fluid was believed to be minimal since (1) there was no relationship between the number of blastocysts recovered from each flushing and the calcium content, and (2) the elevated levels of calcium were observed in both the pregnant and the nonpregnant horn of unilaterally pregnant animals at the time of embryonic elongation.

\section{DISGUSSION}

It seems likely that the metabolism of endometrial zinc is under the control of progesterone. In rabbit and human endometrium (Lutwak-Mann \& McIntosh, 1969; Hagenfeldt et al., 1973), the concentration of zinc rose during the luteal phase and, in the pseudopregnant rabbit, regression of the corpora lutea was associated with a decline in zinc concentration by Day 16 to the levels found in non-pregnant animals. The high and constant levels of zinc observed in the endometrium of roe deer might therefore be explained by the fact that the corpora lutea are active throughout delayed implantation in this species (Short \& Hay, 1966). The zinc concentration observed during delayed implantation, $16.63 \pm 2 \cdot 25 \mu \mathrm{g} / \mathrm{g}$ wet $\mathrm{wt}$, correlates well with the $17 \cdot 2 \pm 2 \cdot 8 \mu \mathrm{g} / \mathrm{g}$ wet wt recorded for the rabbit endometrium on Days 5 to 7 of pregnancy or pseudopregnancy (McIntosh \& Lutwak-Mann, 1972). The slight decrease in zinc concentration during the phase of rapid embryonic growth in the roe deer was probably due to an increase in the water content of the tissues as a result of the marked endometrial oedema observed at this time (Aitken et al., 1973). The function of zinc in the endometrium is not known at the present time but it has been suggested that it plays an important rôle in the binding of steroid hormones, particularly oestradiol-17 $\beta$, to receptor proteins in the endometrium (Emanuel \& Oakey, 1969). A little zinc may also be incorporated into zinc-containing enzymes, such as carbonic anhydrase (an enzyme shown to be active in the endometrium of roe deer during delayed implantation by Short \& Hay, 1966), alkaline phosphatase and lactic dehydrogenase.

The negligible quantities of zinc detected in the uterine flushings during delayed implantation correspond to the results obtained by McIntosh \& Lutwak-Mann (1972), who showed that the low concentration of zinc in the uterine fluids of the rabbit was due to a slow uptake of this element from the endometrium. A strict control on the transport of zinc into the uterine lumen might be expected since, in the rabbit, high levels of intraluminal zinc inhibit blastocyst implantation (Zipper, Mendel \& Prager, 1970).

At the present time, there is insufficient evidence available to evaluate either the cause or the significance of the progressive rise in endometrial calcium 
during delayed implantation. It is possible that the very high values observed during the phase of rapid embryonic growth are associated with the increased vascularity and oedema of the uterus at this time (Aitken et al., 1973). The gradual rise in calcium concentration before the onset of embryonic elongation may also be related to the accumulation of a calcium-rich secretion in the endometrial glands during this period (Aitken et al., 1973).

Since the release of this secretion into the uterine lumen in January was correlated with a marked rise in the calcium content of the uterine flushings, it seems likely that the product of the endometrial glands is indeed rich in calcium. It is also possible that some of the calcium present in the uterine flushings was derived from the transudation of fluid from the endometrial capillaries. An increase in the permeability of the endometrial capillaries of the roe deer during the phase of rapid embryonic growth is indicated by the marked oedema of the endometrium during this phase; the oedema, in turn, is probably a consequence of the simultaneous increase in plasma oestrogen concentration (R. J. Aitken and T. Brinck-Johnsen, unpublished observations). A similar origin could also be postulated for the high levels of calcium observed in the uterine fluid of the cow (Schultz et al., 1971) and rabbit (Lutwak-Mann \& McIntosh, 1971) during oestrus. The significant increase in the calcium content of uterine flushings collected in January from animals still carrying blastocysts in diapause compared with those from animals in earlier stages of delayed implantation indicated that the concentration of calcium in the uterine lumen started to rise just before the onset of embryonic growth.

The changes observed in the calcium content of the endometrium and uterine flushings, and the fact that the concentration of endometrial zinc is maintained at a high level throughout delayed implantation, indicates that these elements play an important, though undetermined, rôle in the progestational uterus.

\section{ACKNOWLEDGMENTS}

Grateful thanks are due to the Forestry Commission and in particular Mr R. Whitta, Mr D. Green, Mr D. Rands, Mr F. Johnson, Mr T. Banham and Mr C. Halls for shooting the deer. I should also like to thank Dr J. E. A. McIntosh for his advice on the determination of calcium and zinc in endometrial digests, and Dr C. Lutwak-Mann and Dr R. V. Short for help and encouragement throughout the study. The work was supported by an M.R.G. Research Studentship.

\section{REFERENCES}

Aitken, R. J. (1974) Delayed implantation in roe deer (Capreolus capreolus). 7. Reprod. Fert. 39, 225.

Aitken, R. J., Burton, J., Hawkins, J., Kerr-Wirson, R., Short, R. V. \& Steven, D. H. (1973) Histological and ultrastructural changes in the blastocyst and reproductive tract of the roe deer (Capreolus capreolus) during delayed implantation. 7. Reprod. Fert. 34, 481.

Emanuel, M. B. \& OAKEy, R. E. (1969) Effect of $\mathrm{Zn}^{+{ }^{+}}$on the binding of oestradiol-17 $\beta$ to a uterine protein. Nature, Lond. 223, 66.

Hagenfeldr, K., Plantin, L. O. \& Diczfalusy, E. (1970) Trace elements in the human endometrium. 1. Zinc, copper, manganese, sodium and potassium concentrations at various phases of the normal menstrual cycle. Acta endocr., Copenh. 65, 541.

Hagenfeldt, K., Plantin, L. O. \& Diczfalusy, E. (1973) Trace elements in the human endometrium. 2. Zinc, copper and manganese levels in the endometrium, cervical mucus, and plasma. Acta endocr., Copenh. 72, 115. 
HeAp, R. B. (1962) Some chemical constituents of uterine washings. A method of analysis with results from various species. 7 . Endocr. 24, 367.

Lutwak-Mann, G. \& McINtosh, J. E. A. (1969) Zinc and carbonic anhydrase in the rabbit uterus. Nature, Lond. 221, 1111.

Lutwak-Mann, G. \& McIntosh, J. E. A. (1971) Galcium content and uptake of ${ }^{45} \mathrm{G}$ in rabbit blastocysts and their environments. F. Reprod. Fert. 27, 471.

MaIntosh, J. E. A. \& Lutwak-MaNN, G. (1972) Zn transport in rabbit tissues. Some hormonal aspects of the turnover of $\mathrm{Zn}$ in female reproductive organs, liver and body fluids. Biochem. F. 126, 869 .

Mrtcheld, B. (1963) Determination of age in Scottish red deer from growth layers in dental cement. Nature, Lond. 198, 350.

Mrrcheld, B. (1967) Growth layers in dental cement for determining the age of red deer (Cervus elaphus L.). F. Anim. Ecol. 36, 279.

Schultz, R. H., Fahning, M. L. \& Graham, E. F. (1971) A chemical study of uterine fluid and blood serum of normal cows during the oestrous cycle. 7 . Reprod. Fert. 27, 355.

Short, R. V. \& Hay, M. F. (1966) Delayed implantation in the roe deer (Capreolus capreolus). Symp. zool. Soc. Lond. 15, 173.

Zipper, J., Mendel, M. \& Prager, R. (1970) Suppression of fertility by intrauterine copper and zinc in rabbits. Am. $\mathcal{F}$. Obstet. Gynec. 105, 529. 